\title{
Sad or Happy? The Effects of Emotions on Stated Preferences for Environmental Goods
}

\author{
Nick Hanley ${ }^{1}$ - Christopher Boyce ${ }^{2}$ - Mikołaj Czajkowski ${ }^{3}$ - Steve Tucker $^{4}$. \\ Charles Noussair $^{5}$ - Michael Townsend ${ }^{6}$
}

Accepted: 16 June 2016 / Published online: 18 July 2016

(C) The Author(s) 2016. This article is published with open access at Springerlink.com

\begin{abstract}
A substantial literature in behavioural science and psychology shows that emotions affect human choices and values. This paper investigates whether such emotional impacts are also present in stated choice experiments for environmental goods. If this were so, it would introduce an additional element of context dependence to the welfare measures derived from such methods, and would be at odds with the rational choice model underlying welfare economics. A laboratory experiment using three different emotion treatments was combined with a stated preference choice experiment concerned with changes in coastal water quality and fish populations in New Zealand. No statistically significant effects of changes in emotional state on estimated preference parameters, willingness to pay or the randomness of choices were found. The paper concludes by questioning, why such a contrast exists with empirical findings in behavioural science.
\end{abstract}

Keywords Choice experiments · Behavioral economics · Environmental valuation · Emotions · Cost-benefit analysis

JEL Classification Q51 - Q57 · D03 · D87

Electronic supplementary material The online version of this article (doi:10.1007/s10640-016-0048-9) contains supplementary material, which is available to authorized users.

Nick Hanley

ndh3@st-andrews.ac.uk

1 Department of Geography and Sustainable Development, University of St Andrews, Irvine Building, North Street, St Andrews, Fife KY16 9AL, Scotland, UK

2 Behavioural Science Centre, University of Stirling, Stirling, Scotland, UK

3 Department of Economics, University of Warsaw, Warsaw, Poland

4 School of Management, University of Waikato, Hamilton, New Zealand

5 Eller College of Management, University of Arizona, Tucson, AZ, USA

6 National Institute for Water and Atmosphere Ltd, Hamilton, New Zealand 


\section{Introduction}

What determines the variation in stated preferences for environmental goods? Researchers have investigated the effects on willingness to pay (WTP) of observables such as income (Jacobsen and Hanley 2009), experience with and knowledge of the good (LaRiviere et al. 2014; Czajkowski et al. 2015), and location (Schaafsma et al. 2013; Termansen et al. 2013); as well as exploring ways of modelling un-observed heterogeneity (Hynes et al. 2008). In this paper, we explore the possible impacts of another set of factors on the variation in stated preferences, namely an individual's emotional state at the time of the survey.

A large literature in behavioural sciences and psychology suggests that emotions affect people's decisions in a wide range of settings (Loewenstein 2000; Elster 1998). This evidence, which we summarize in Sect. 2 of this paper, is largely obtained in the context of actual choices and behaviours. It might therefore be reasonable to speculate that emotions will also affect stated choices. However, behavioural intention is not identical to actual behaviour. For example, the theory of planned behaviour (see e.g., Ajzen 1991) suggests that a behaviour is influenced primarily by the intention to achieve the behaviour and the degree of perceived (and actual) control over the behaviour. Although the theory of planned behaviour has been shown to account for substantial amounts of variance in intention and behaviour (Armitage and Conner 2001), the relationship can depend upon intermediated factors such as individual attitudes to the behaviour in question and social norms about the behaviour (Ajzen 1991). Thus, whilst emotions have been shown to affect actual behaviour, they might not necessarily affect stated choices in the same way, if for example emotions influence intentions or perceptions about control (Ruthig et al. 2007). Nevertheless, it would be expected that if emotions were to influence intentions or control perceptions, they may still play an important role, albeit a slightly different one to that of actual behaviour, in stated choices. It is this role which this paper investigates.

If there are effects of changing emotions on revealed or stated choices, this could pose a challenge to the interpretation of benefit-cost measures of value, since these are based on a model of rational choice and stable, consistent, and complete preference sets for each individual (Brown et al. 2008; Rabin 1998). If revealed or stated values are dependent upon an individual's emotional state at the time benefits or costs are measured, then this introduces a source of context dependence which the Kaldor-Hicks criterion underlying Cost-Benefit Analysis (CBA) was not intended to deal with. ${ }^{1}$ For example, a change in emotional state post project implementation could mean that those who gain are no longer willing to pay enough to compensate losers, even though the project had passed the CBA test before implementation.

In this paper, we focus on a specific class of emotions referred to as incidental emotions. These emotions, such as sadness or happiness, occur at the moment of a choice decision, but are un-related to the payoffs from the decision at hand. Our experimental set-up uses stated choice modelling to estimate preferences over changes in an environmental good in an experimental laboratory setting, with a series of treatments designed to induce a given emotional state in respondents prior to their stated choices. The emotional states are sadness, happiness and a neutral state. We induce these different incidental emotions using an established practice in behavioural science. We subsequently test whether the inducement procedure worked in terms of inducing the targeted emotional state, and find that it did. The materials used to induce the targeted emotional state are un-related to the environmental good, since otherwise

\footnotetext{
1 Tests for whether a project or policy will improve social well-being were proposed independently by Kaldor and by Hicks in the 1930s, but are now usually combined together in what is also known as the "potential pareto improvement" criterion. See Hanley and Barbier (2009) for more detail.
} 
participants would feel they were being manipulated in terms of stating their choices for changes in the good (beach quality).

Our main hypothesis is that variation in emotional state experienced prior to participation in the stated choice experiment has a significant effect on stated preferences (and thus on Willingness To Pay) for changes in an environmental good. That is, we test whether variations in emotional state can help explain preference heterogeneity. Based on inferences one can draw from the psychology literature, we also test whether a respondent's emotional state impacts on the randomness with which they make their choices in the stated preference exercise.

\section{Emotional Effects on Choice and Behaviour}

Emotions are thought to enter into the decision making process in three important ways (Rick and Loewenstein 2008). First, certain emotions may be anticipated directly from the outcome of the decision itself and materialize at some future point i.e. through comparing the expected happiness from purchasing a new book compared with going to a football game. Second, there are emotions, referred to as integral emotions, which occur at the moment of decision and are directly related to the decision at hand (Lerner et al. 2014). For example, the decision itself may pose some element of risk and therefore evoke feelings of fear, or even pleasure (Loewenstein et al. 2001). As Rick and Loewenstein (2008) argue, neither of these types of emotions pose a major challenge for the rational choice framework of welfare economics and mainstream economic consumer theory, since they influence the utility associated with choice alternatives, and therefore should affect people's choices.

The third way in which emotions can influence behaviour is through a consideration of "incidental emotions", emotions which occur at the moment of the decision but are irrelevant to its payoffs. Incidental emotions, such as anger, fear, surprise, disgust, joy, or sadness, may be present whilst individuals are making important decisions for many different reasons. For example, an individual may be sad from thinking about an argument they had that morning, or from a recent bereavement, or they might be happy from having just watched an uplifting film, or just from the fact that it happens to be a sunny day. Incidental emotions are known to influence high level cognitive processes, such as interpretation, judgement, decision-making, and reasoning (Blanchette and Richards 2010) and it has thus been suggested that incidental emotions have the power to "reprogram us into effectively different people" (Loewenstein 2010). On the basis that sunshine causes greater feelings of happiness (e.g., Schwarz and Clore 1983) the amount of sunshine in a given day has, for example, been shown to influence stock market performance (Hirshleifer and Shumway 2003; Kamstra et al. 2003). Further, when a country's team is eliminated from the World Cup, stock market returns decline (Edmans et al. 2007). The psychological evidence thus suggests a strong likelihood that incidental emotions will influence an individual's stated preferences for environmental goods, even though they do not affect the payoffs from choice alternatives. If this was the case there may be a fundamental threat to conventional economic models. However, this proposition has yet to be tested.

A substantial amount of this research highlighting the importance of incidental emotions has come from experiments where researchers induce specific emotions within an individual prior to them carrying out some decision-based task (Lerner et al. 2014). Before the task, researchers randomize individuals into an "emotion manipulation", whereby a procedure such as watching film clips, reading stories, or listening to music, is used to elicit specific emotions (Gilet 2008; Westermann et al. 1996). Johnson and Tversky (1983) provided one 
of the first empirical demonstrations that inducing a specific emotional state, via reading newspaper stories, resulted in different risk perceptions. Since then, notable findings include that the endowment effect was eliminated when inducing disgust and completely reversed when inducing sadness (Lerner et al. 2004). Andrade and Ariely (2009) demonstrate, using ultimatum and dictator games, that the emotions induced via showing a film can endure by not only influencing decisions in the moment but also by influencing subsequent decisions. It has also been shown that when a charity appeal invokes feelings of sympathy, guilt or personal nostalgia, then donations increase (see e.g., Kogut and Ritov (2005); Small and Loewenstein (2003); Ford and Merchant (2010)). Current sexual arousal has also been shown to influence behavioural decisions relating to sex (Ariely and Loewenstein 2005) and when induced with happiness individuals have higher productivity in a paid piece-rate task (Oswald et al. forthcoming). Indeed, there is relatively scant evidence where affective states have not influenced decision-making in some way (Blanchette and Richards 2010).

Based around the mechanisms driving such differences in decisions, positive and negative emotions have been shown to lead to very different ways of processing information. We may expect individuals in a "happy" state to have a higher desire to avoid losses (in our experiment, losses correspond to declines in environmental quality at beaches); whilst being in a happy state generally increases the reliance on heuristic processing and decreases systematic possessing (Blanchette and Richards 2010). Isen et al. (1988) show, for example, that those induced with happiness show a more negative subjective utility for losses than those not induced. As such it is possible that those induced to feel happiness will make relatively quick decisions, be more sensitive to losses, and therefore have a different WTP for changes in environmental quality than those who are not induced to feel happy. Due to greater reliance on heuristics, we also expect happy individuals to make more mistakes i.e. demonstrate more randomness in their choices. Contrastingly, sadness induces more careful and systematic processing over decisions (Bodenhausen et al. 2000). Individuals induced to feel sadness would take more time in making their decisions, make fewer mistakes, and thus exhibit less randomness in their decisions relative to those who are not sad. Further, sad individuals are less reliant on stereotypes and spend more time processing case information (e.g., Bless et al. 1996a, b) suggesting they may be more considerate towards the interests of others (and thus differ in their preferences for public goods which benefit others).

Summing up, an extensive literature in behavioural science and psychology suggests that changes in incidental emotions can alter how people make choices and how they behave. It is thus possible to set out four alternative hypotheses for testing. These are:

\section{Preference heterogeneity effect}

$H_{0}^{1}$ : individuals in a sad or a happy (i.e., non-neutral) emotional state will state different preferences for changes in an environmental good than those in a neutral emotional state. $H_{0}^{2}$ : individuals who are in a happy emotional state will state different preferences for changes in an environmental good than those in a sad emotional state.

\section{Randomness of choice effect}

$H_{0}^{3}$ : individuals in a sad or happy (i.e., non-neutral) state will display a different randomness of stated choices than individuals in a neutral state.

$H_{0}^{4}$ : individuals in a happy emotional state will display a different randomness of stated choices than individuals in a sad emotional state.

We now describe an experiment where these hypotheses are tested. 


\section{Experimental Design}

\subsection{Lab Procedures}

The experiment consisted of 17 sessions conducted in September 2014 at the Waikato Experimental Economics Laboratory at the University of Waikato, New Zealand. A total of 287 subjects participated in the experiment. The participants were university students that were recruited university wide using ORSEE (Greiner 2004). ${ }^{2}$ Some of the participants had participated in previous economics experiments, but none had experience with the emotion elicitation methods employed. All interaction within the experiment took place via private computer terminals. Each session lasted for less than one hour. The time subjects took to complete the survey varied widely, but each session lasted until the last person had completed their tasks and all had then been paid. Participants were paid NZD 20 upon completion of the survey.

We randomized participants into one of three different conditions: a sadness condition, a happiness condition, and a neutral condition. This was done as soon as respondents had entered the lab, and before they were presented with the stated choice experiment. In each treatment, participants were asked to watch a collection of short film clips (approximately 67 minutes in length). The short film clips in each collection had the same valence. "Valence" in psychology refers to the extent to which a particular event or object evokes an attractive (positive valence) or aversive (negative valence) response. Thus those in the sadness condition were shown a collection of films that evoked emotions of sadness i.e. a negative valence, whilst those in the happiness condition were shown a collection of films that evoked emotions of happiness i.e. a positive valence. Those in the neutral condition were shown a collection of films that were neither aversive nor attractive and therefore would be considered to have a neutral valence. The film clips were selected based on prior research which has illustrated the effectiveness of such clips in eliciting specific emotions (Rottenberg et al. 2007; Schaefer et al. 2010). Feinstein et al. (2010) demonstrate that such films have a persistent impact on emotional state, even for patients with amnesia. It has been shown that showing a short film with emotional content before a task is the most effective way to induce a specific emotion (Gilet 2008). Specific clips from well-known films have been used to induce fear (The Shining: Boven et al. 2012), anger (Cry Freedom: Inbar and Gilovich 2011), or happiness (various comedy clips: Forgas and East 2008). Such a technique has been well validated with several attempts to systematically review the effectiveness of different film clips, as well as categorize the precise emotions they elicit (see e.g., Schaefer et al. 2010).

In our survey, we used clips adapted from Feinstein et al. (2010) to elicit two incidental emotions, sadness and happiness, prior to decisions relating to the environment. Typically, studies include neutral conditions which involve showing documentaries relating specifically to nature (e.g., Andrade and Ariely 2009; Forgas and East 2008). To avoid priming subjects with concerns about the environment (given that this was the object over which people were then being asked to make choices), we ensured our neutral condition consisted instead of various non-emotional clips unrelated to the environment. The specific film clips used for each condition are listed in Table 1.

At the end of the choice experiment we carried out a manipulation check and asked participants to report how they felt while they were watching the video clips. We asked two

2 The Online Recruitment System for Economics Experiments (ORSEE) is a subject recruitment and management program specifically designed for economics experiments. More information can be found at http:// www.orsee.org/web/. 
Table 1 Film clips used in each of the experimental conditions. Resources available at http://tinyurl.com/ hnr3jnt

\begin{tabular}{|c|c|c|c|c|c|}
\hline $\begin{array}{l}\text { Experimental } \\
\text { condition }\end{array}$ & Clip 1 & Clip 2 & Clip 3 & Clip 4 & Total time \\
\hline $\begin{array}{l}\text { Sadness (negative } \\
\text { valence) }\end{array}$ & $\begin{array}{l}\text { The Champ (Child } \\
\text { experiences his } \\
\text { hero's } \\
\text { death-2:42) }\end{array}$ & $\begin{array}{l}\text { Born on the 4th of } \\
\text { July (Man } \\
\text { injured from war } \\
\text { has returned } \\
\text { home and is } \\
\text { distraught- } \\
1: 59 \text { ) }\end{array}$ & $\begin{array}{l}\text { Forest Gump } \\
\text { (Man is at the } \\
\text { graveside of his } \\
\text { love-2:01) }\end{array}$ & & $6: 42$ \\
\hline $\begin{array}{l}\text { Happiness } \\
\text { (positive } \\
\text { valence) }\end{array}$ & $\begin{array}{l}\text { Ladder } 49 \text { (Man } \\
\text { finds out his } \\
\text { wife is } \\
\text { pregnant-1:18) }\end{array}$ & $\begin{array}{l}\text { Love actually } \\
\text { (Man proposes } \\
\text { to a } \\
\text { woman-2:21) }\end{array}$ & $\begin{array}{l}\text { Love Actually } \\
\text { (People meeting } \\
\text { loved ones at the } \\
\text { airport-1:19) }\end{array}$ & $\begin{array}{l}\text { Indiana Jones } \\
\text { (Children return } \\
\text { home to their } \\
\text { parents-1:16) }\end{array}$ & $6: 14$ \\
\hline Neutral & $\begin{array}{l}\text { Stock market } \\
\text { report (Woman } \\
\text { reports on the } \\
\text { stock } \\
\text { market-1:30) }\end{array}$ & $\begin{array}{l}\text { Golf grip video } \\
\text { (Man describes } \\
\text { how to grip a } \\
\text { golf club-1:51) }\end{array}$ & $\begin{array}{l}\text { Abstract painting } \\
\text { (Woman } \\
\text { describes acrylic } \\
\text { painting } \\
\text { techniques- } \\
\text { 1:06) }\end{array}$ & $\begin{array}{l}\text { Antiques auctions } \\
\text { (Man describes } \\
\text { items sold at an } \\
\text { antiques } \\
\text { auction-1:26) }\end{array}$ & $5: 53$ \\
\hline
\end{tabular}

questions relating to valence (the intrinsic attractiveness: positive or negative): "While I was watching the film I felt. .. 1 = sad (bad), 4 = neither happy nor sad (neither bad nor good), 7 = happy (good)".

\subsection{The Choice Experiment}

We designed a choice experiment (Hensher et al. 2005) to elicit preferences for an environmental good, namely visits to the beach on the North Island of New Zealand. Choice experiments describe the objects of choice (here, beach visits) using the attributes of these objects, and the levels which they can take. Beach visits within the North Island of New Zealand were described using a set of three attributes, based on discussions with scientists from the National Institute for Water and Atmosphere. The three environmental attributes corresponded to three important environmental quality issues currently impacting on New Zealand coastal ecosystems, namely sediment loads, nutrient pollution, and declining fish stocks. Travel distance was included as a proxy for the price of a beach visit. The choice situation did not ask participants to express a WTP for a hypothetical increase in an environmental good. Rather, it asked them to make choices about which beach to visit on a day trip, where alternative beaches were described in terms of these three environmental attributes and a travel distance. From these choices, the relative preferences and WTP for changes in each environmental attribute could then be inferred, rather like in a random utility site choice model estimated with revealed preference data on recreation behaviours.

Having viewed one of the three sets of film clips, respondents read the following text:

We now want to ask you some questions about the New Zealand coast. Many of us enjoy a visit to the beach, whether to go surfing, swimming, or just hanging out. Many people also enjoy fishing and boat trips. The state of the environment can affect peoples' experiences during such visits, and may be one of the factors determining 
which beaches they choose to visit. Most of these environmental conditions - such as water quality - are partly determined by how we manage our coastal areas (for example, how much money is spent on pollution control).

Imagine that you have decided to take a day trip to a beach in this area, and are thinking about where to go. On the next screens, you'll see a number of options. We'd like you to make a choice in each case about which beach you'd prefer to visit. Whilst there are many factors determining where you might want to go, these options are all concerned with the environmental conditions at different beaches. Another important factor is obviously how far you would have to travel, so you will see some information in the choice sets about this too. You can assume that it is safe to surf or swim at all of these beaches.

Respondents were then told about the attributes which would describe their choices. The first attribute used to describe beach visits was Water Quality. Water Quality was described in the following way:

WATER QUALITY is important so that we can swim safely without getting sick, keep the animals and plants that live in the sea healthy and to keep the sea looking beautiful. Water entering the coastal zones is affected by human wastes and can be laden with nutrients and other contaminants from farmland. If we take no further action, with a growing population and reduced effectiveness of infrastructure over time, water quality will get worse. This may cause more beach closures (due to pollution by "coliforms" or algal blooms) in certain places. However, if we increase our efforts we will be able to maintain water quality to the current standards we experience (likelihood of beach closures remains similar to the present) and further efforts could actually see an improvement in water quality (reduced risks of beach closures, no algal blooms, and healthier waterways).

In the choices below, you will find that water quality might take one of 3 levels:

- Poor water quality - high levels of nutrients, algal blooms likely

- Good water quality

- Very good water quality - nutrient levels are greatly reduced, algal blooms very unlikely

The second attribute used was sediments. Many areas of the New Zealand coastline have suffered from increased sediment loads, which have resulted in a change in water clarity, the loss of sand areas, and the increased growth of mangroves which greatly impedes access to the water. Respondents were provided with the following information:

SEDIMENTS affect the way we experience the coast, from the clarity of the water (how far down you can see) to underfoot conditions. Changes in land-uses mean that sediment arriving in our harbours and estuaries has increased. This has caused a muddying of many shores and high levels of turbidity that result in the water being murky and unattractive. If we take no further action, sediment will continue to accumulate at the coast and areas of muddy sediment will increase (in coverage and in muddiness). In some places, this will result in further expansion of mangroves. While we can't entirely remove the sediment problem, it is possible to reduce its impacts. With an increased effort in storm-water management areas, we may also be able to improve on the current situation, leading to cleaner, bluer water) and less muddy shores.

In the choices below, you will find that water quality might take one of three levels:

- High levels of sediment - water is very cloudy, beaches become muddy

- Medium levels of sediment 
- Low levels of sediment - water is very clear, beaches stay sandy

The third attribute used to describe visits to the beach was fish populations. Fish populations, both in terms of their size and diversity, are likely to be important for very popular recreational activities such as sea angling, scuba diving, and snorkelling. Respondents were provided with the following information (note that we focus on changes in fish populations, rather than absolute levels):

FISH POPULATIONS many people like to go fishing, for example for snapper. Others like to just know that there are healthy fish stocks in the sea. How good fish stocks are depend on how the coastal environment is managed. Right now, fish populations are under pressure from over-fishing and from water pollution. We can take actions to reduce these pressures, but unless we do so, stocks might continue to decline.

In the choices below, you will find that fish populations might take one of three levels:

- Declining - fish populations are falling due to too much pollution and too much fishing

- Stable

- Increasing - there are healthy and expanding fish populations of fish such as snapper.

Finally, we included a price or cost attribute to allow welfare measures to be calculated from the choice responses. People in New Zealand currently pay for some of the costs of water pollution control through their regional and local taxes, but not everyone pays (e.g., students do not), whilst the link between recreational beach quality and variations in such taxes is unclear. Therefore, we did not use regional or local taxes as a bid vehicle, unlike in some similar studies (e.g., Hanley et al. 2006). Access to beaches in New Zealand is free in the sense of no entry fee being levied for access, meaning that we could not use an entry fee as the price attribute. However, individuals do pay to travel to beaches through fuel costs, and so travel distance was used as a price proxy for each choice option. Several environmental choice experiment studies have used travel costs as the price attribute (e.g., Hynes et al. 2013; Christie et al. 2007). Values for possible distances were chosen based on a maximum two-hour, one-way distance from Hamilton, New Zealand to a set of actual beaches with which respondents might be familiar. The highest value for distance was thus set at $120 \mathrm{~km}$; the shortest distance was set as $30 \mathrm{~km}$.

Given this set of attributes and levels, three blocks of 8 choice sets were constructed. Each choice set contains three choice options: visit beach $\mathrm{A}$, visit beach $\mathrm{B}$, or visit neither and make no beach trip on that choice occasion. Based on random utility theory, we expect each individual to choose that option in each choice set (A, B, neither) which maximizes utility from that choice occasion, independently of any emotional manipulation. Each individual faces 8 choice cards and so provides 8 observations of choices between three alternatives. We model their choices as a function of the attributes and levels in each choice option, and the emotional treatment which they received. An example of the choice card is included as Table 2.

\subsection{Lab Procedure}

Each session proceeded as follows: (1) upon arrival to the laboratory, participants were free to choose any computer desk to use for the session. The desks are specifically designed with privacy walls surrounding to minimize external influences. (2) Once everyone was seated, a short welcome speech was provided by the experimenter after which the survey program was run simultaneously for everyone. (3) Participants were initially provided a screen asking 
Table 2 Example Choice Card

\begin{tabular}{llll}
\hline & Beach A & Beach B \\
\hline Water quality & Good & Very good & $\begin{array}{c}\text { Go to neither I would not want to visit either of } \\
\text { these beaches and would stay at home instead }\end{array}$ \\
Sediments & Low & High \\
Fish populations & Stable & Declining \\
How far from where you live? & $120 \mathrm{~km}$ & $30 \mathrm{~km}$ \\
I would choose: & $\square$ & $\square$ & $\square$ \\
\hline
\end{tabular}

their area of academic study and where they are from. Once everyone completed these two questions, the movie clips started simultaneously for everyone. All subjects were provided headphones for viewing the movies. (4) Upon completion of the movie, participants took part in the choice experiment survey. (5) Finally, participants answered a series of questions regarding their personal traits and a self-assessment of emotional state induced while watching the movie. Participants were asked to wait quietly until everyone was finished and then were called back one at a time to be privately paid their participation fee.

\section{Econometric Approach}

The theoretical foundations for the analysis of our choice experiment data are provided by the random utility theory (McFadden 1974). Formally, assume that the utility $U$ derived from respondent $i$ 's choice of alternative $j$ in choice task $t$ can be expressed by:

$$
U_{i j t}=\mathbf{X}_{i j t} \boldsymbol{\beta}_{i}+e_{i j t},
$$

where the utility expression is separable in attribute levels $X$ with the vector of associated parameters $\beta,{ }^{3}$ and a stochastic component $e$ allowing for other factors than those observed by a modeller to affect individual's choices. The stochastic component of the utility function is of unknown, with possibly heteroskedastic, individual-specific, variance $\left(\operatorname{var}\left(e_{i j t}\right)=s_{i}^{2}\right)$. Identification of the model is typically assured by normalizing this variance, making the error term $\varepsilon_{i j t}=e_{i j t} \cdot \sigma_{i}$, where $\sigma_{i}=\pi /\left(\sqrt{6} s_{i}\right)$, identically and independently, extreme value type 1 distributed with a constant variance $\operatorname{var}\left(\varepsilon_{i j t}\right)=\pi^{2} / 6$. This specification of the error term leads to convenient expression of choice probabilities — an individual will choose alternative $j$ if $U_{i j t}>U_{i k t}$, for all $k \neq j$, and the probability that alternative $j$ is chosen from a set of $J$ alternatives becomes

$$
P(j \mid J)=\frac{\exp \left(X_{i j t}\left(\sigma_{i} \boldsymbol{\beta}_{i}\right)\right)}{\sum_{k=1}^{J} \exp \left(X_{i k t}\left(\sigma_{i} \boldsymbol{\beta}_{i}\right)\right)} .
$$

Note that in the above specification, as a result of normalization the preference parameters become $\sigma_{i} \boldsymbol{\beta}_{i}$. Due to the ordinal nature of utility (the preference parameters do not have a direct interpretation anyway), this specification still represents the same preferences for individual $i$. Note also that emotional state does not enter the utility function, and so should

\footnotetext{
3 Note that the coefficients are indexed by respondents-in the multinomial logit model all respondents are assumed to have exactly the same preference parameters, while in the mixed logit model respondents' coefficients can differ and are assumed to follow an a priori specified multivariate parametric distributions.
} 
not influence choices, unless it changes the preference parameters $\beta$ or the scale parameter $\sigma$.

We next use this approach to test if the (objective) emotional treatments or the (subjectively reported) emotional states of the respondents (represented jointly by a vector of covariates z) lead to significant differences in their observed choices. Following Czajkowski et al. (2016) and representing the individual-specific random taste parameters by a vector of their population means $\mathbf{b}$ and individual-specific deviations from these means $\boldsymbol{v}_{i}{ }^{4}: \boldsymbol{\beta}_{i}=\mathbf{b}+\mathbf{z}_{i} \boldsymbol{\phi}+$ $\boldsymbol{v}_{i} \exp \left(\mathbf{z}_{i} \psi\right)$. The parameters $\phi$ represent the effect of emotions on means and the parameters $\psi$ represent the effect of emotions on standard deviations of random taste parameters $\boldsymbol{\beta}_{i}$.

Alternatively, to test if emotions influence stochastic component of utility function $e$, i.e. the level of apparent randomness of respondent's choices. This is operationalized by specifying the scale parameter to be a function of emotions-related covariates $\mathbf{z}$ : $\sigma_{i}=\pi /\left(\sqrt{6} s_{i}\right) \exp \left(\mathbf{z}_{i} \xi\right)$. The parameters $\xi$ represent the effect of emotions on scale. Note that scale is inversely related to variance of error term, and therefore positive values of $\xi$ would lead to smaller variance of $e$.

Note that in the case of binary (e.g., dummy-coded) $\mathbf{z}$ it is not possible to identify a model in which $\mathbf{z}$ are simultaneously used as explanatory variables of means and standard deviations of random preference parameters and as an explanatory variable of scale. ${ }^{5}$ This is because $\boldsymbol{\beta}_{i}$ and $\sigma_{i}$ always enter the model as a product, and hence imposing particular constraints on $\phi$ and $\psi$ is equivalent of $\xi$ (Hess and Rose 2012). ${ }^{6}$ For this reason, we separately test if we find the effect of emotions on means $\mathbf{b}$ and standard deviations $\mathbf{s}$ of the random preference parameters (i.e., we test if $\phi$ and $\psi$ are significantly different from 0 ) and then test if emotions affect the scale parameter $\sigma_{i}{ }^{7,8}$

\section{Results}

In this section we present the results of our empirical investigation into whether emotional states influence individual's preferences. We start with the results of ordered probit models in which respondents' Likert-scale responses to questions regarding whether while watching the film clips they felt sad compared to happy and felt bad compared to good (Table 3 ). The results show that our treatments significantly influenced the extent to which respondents selfreported they felt sad or happy (panel A) and bad or good (panel B) - i.e., our experimental

\footnotetext{
4 For example, for uncorrelated normally distributed $\boldsymbol{\beta}_{i}, \mathbf{v}_{i}=\mathbf{s} \boldsymbol{S}_{i}$ where $\mathbf{s}$ is a diagonal matrix of standard deviations and $\boldsymbol{\zeta}_{i}$ is a vector of random, standard normally distributed unobserved taste variations associated with preference parameters (with mean vector 0 and covariance (identity) matrix I).

5 In the case of $\mathbf{z}$ composed of continuous covariates, it is theoretically possible to simultaneously estimate $\phi, \psi$ and $\xi$, however, note that identification would only be possible because of allowing for a more flexible (non-linear) functional form, making interpretation of the estimated parameters unrelated to separate effects for preference or scale parameters.

6 Observing an effect for the scale parameter is equivalent to observing a simultaneous and equal effect for all preference parameters (means and standard deviations), or interpreted differently, an effect for the error term of the utility function which can be thought of as the level of randomness of the choices, as observed by a researcher.

7 Even if the former specification is significantly better fitted to data, it does not mean that there is no effect of covariates $\mathbf{z}$ on scale. In such a case, a researcher can only conclude that besides the scale effect (which may or may not exist) there are also other effects influencing random parameters means and standard deviations.

8 The models were estimated in Matlab. The software used here (estimation package for DCE data) is available from github.com/czaj/DCE under CC BY 4.0 license. The dataset, additional results, and estimation codes are available from the authors upon request.
} 
Table 3 The effects of emotional treatments on individuals' self-reported emotional states-the results of ordered probit models

\begin{tabular}{|c|c|c|}
\hline & $\begin{array}{l}\text { (A) sad-happy } \\
\text { Coefficient } \\
\text { (SE) }\end{array}$ & $\begin{array}{l}\text { (B) bad-good } \\
\text { Coefficient } \\
\text { (SE) }\end{array}$ \\
\hline \multicolumn{3}{|c|}{ Index probability function probability parameters } \\
\hline Happy treatment & $\begin{array}{l}1.3987^{* * *} \\
(0.1635)\end{array}$ & $\begin{array}{l}1.1684^{* * *} \\
(0.1574)\end{array}$ \\
\hline Sad treatment & $\begin{array}{l}-2.2936^{* * *} \\
(0.1660)\end{array}$ & $\begin{array}{l}-1.4130^{* * *} \\
(0.1585)\end{array}$ \\
\hline \multicolumn{3}{|c|}{ Threshold parameters for index function } \\
\hline Constant & $\begin{array}{l}2.6731^{\text {**** }} \\
(0.1210)\end{array}$ & $\begin{array}{l}2.5598^{* * *} \\
(0.1153)\end{array}$ \\
\hline$\eta_{1}$ & $\begin{array}{l}0.7441^{* * *} \\
(0.1000)\end{array}$ & $\begin{array}{l}0.6529^{* * *} \\
(0.0984)\end{array}$ \\
\hline$\eta_{2}$ & $\begin{array}{l}1.5492^{* * *} \\
(0.1108)\end{array}$ & $\begin{array}{l}1.1778^{* * *} \\
(0.1000)\end{array}$ \\
\hline$\eta_{3}$ & $\begin{array}{l}3.0243^{* * *} \\
(0.1042)\end{array}$ & $\begin{array}{l}2.7623^{* * *} \\
(0.0936)\end{array}$ \\
\hline$\eta_{4}$ & $\begin{array}{l}3.8369^{* * *} \\
(0.1014)\end{array}$ & $\begin{array}{l}3.5245^{* * *} \\
(0.0928)\end{array}$ \\
\hline$\eta_{5}$ & $\begin{array}{l}4.7355^{* * *} \\
(0.1326)\end{array}$ & $\begin{array}{l}4.3084^{* * *} \\
(0.1214)\end{array}$ \\
\hline \multicolumn{3}{|l|}{ Model characteristics } \\
\hline Log-likelihood (constant only) & -541.7879 & -498.7284 \\
\hline Log-likelihood & -388.1543 & -498.7284 \\
\hline McFadden's pseudo $\mathrm{R}^{2}$ & 0.2836 & 0.1913 \\
\hline $\mathrm{AIC} / n$ & 2.7610 & 2.8660 \\
\hline$n$ (observations) & 287 & 287 \\
\hline$k$ (parameters) & 8 & 8 \\
\hline
\end{tabular}

Individuals were asked to respond to the following statements: While I was watching the film I felt. . .1 = sad, $4=$ neither happy nor sad, $7=$ happy; $1=$ bad, $4=$ neither bad nor good, $7=\operatorname{good}$

***, ${ }^{* *},{ }^{*}$ represent significance at $1,5,10 \%$ level, respectively

stimuli worked. We then turn to presenting the results of the mixed logit models accounting for the influence of emotional states on preferences, which are presented in detail in Tables 6, 7, 8 and 9, and are summarized in Table 4 which is used to succinctly compare all of the modelling approaches reported in this section. Finally, Table 5 presents the results of statistical tests of our research hypotheses.

To establish a baseline, panel A of Table 6 and the first row of Table 4 presents a general model which ignores which emotional treatment group participants were in. The variable names represent improvements in water quality levels- $\operatorname{good}\left(W Q_{1}\right)$ and very good $\left(W Q_{2}\right)$ vs. the current poor water quality (reference level); sediment levels-medium $\left(S E D_{1}\right)$ and low $\left(S E D_{0}\right)$ vs. the current high levels of sediments (reference level); fish populations - stable $\left(F_{S H} H_{1}\right)$ and increasing $\left(F_{S} H_{2}\right)$ vs. the current declining levels; the effects of changes in 
Table 4 Summary of the results of modelling the effects of emotional treatments and self-reported emotional states on individuals' preference or scale parameters

\begin{tabular}{|c|c|c|c|c|c|}
\hline $\begin{array}{l}\text { Model } \\
\text { specification }\end{array}$ & Log-likelihood & $k$ (parameters) & $\begin{array}{l}\text { McFadden's } \\
\text { pseudo } \mathrm{R}^{2}\end{array}$ & $\begin{array}{l}\text { Ben-Akiva } \\
\text { Lerman's } \\
\text { pseudo } \mathrm{R}^{2}\end{array}$ & $A I C / n$ \\
\hline (A) Baseline & -1913.91 & 16 & 0.2163 & 0.4477 & 1.6812 \\
\hline $\begin{array}{l}\text { (B) Effect of } \\
\text { emotional treatments } \\
\text { (separate) on } \\
\text { preferences }\end{array}$ & -1903.61 & 48 & 0.2205 & 0.4494 & 1.7009 \\
\hline $\begin{array}{l}\text { (C) Effect of } \\
\text { emotional treatments } \\
\text { (combined) on } \\
\text { preferences }\end{array}$ & -1908.92 & 32 & 0.2183 & 0.4485 & 1.6911 \\
\hline $\begin{array}{l}\text { (D) Effect of } \\
\text { emotional treatments } \\
\text { (separate) on scale }\end{array}$ & -1911.86 & 18 & 0.2171 & 0.4479 & 1.6812 \\
\hline $\begin{array}{l}\text { (E) Effect of emotional } \\
\text { treatments (combined) } \\
\text { on scale }\end{array}$ & -1913.57 & 17 & 0.2164 & 0.4477 & 1.6818 \\
\hline $\begin{array}{l}\text { (F) Effect of self- } \\
\text { reported emotional } \\
\text { states on preferences }\end{array}$ & -1902.08 & 48 & 0.2211 & 0.4501 & 1.6996 \\
\hline $\begin{array}{l}(\mathrm{G}) \text { Effect of self- } \\
\text { reported emotional } \\
\text { states (absolute } \\
\text { strength) on } \\
\text { preferences }\end{array}$ & -1906.11 & 48 & 0.2195 & 0.4493 & 1.7031 \\
\hline $\begin{array}{l}(\mathrm{H}) \text { Effect of self- } \\
\text { reported emotional } \\
\text { states on scale }\end{array}$ & -1909.75 & 18 & 0.2180 & 0.4484 & 1.6794 \\
\hline $\begin{array}{l}\text { (I) Effect of self- } \\
\text { reported emotional } \\
\text { states (absolute } \\
\text { strength) on scale }\end{array}$ & -1913.07 & 18 & 0.2166 & 0.4481 & 1.6823 \\
\hline
\end{tabular}

travel distance to a beach (DIST) and respondents' propensity to choose the opt-out ('go to neither') option $(O O)$. The coefficients correspond to utility function parameters and although do not have direct interpretation, their signs and relative values represent the marginal utility an individual derives from an alternative with a particular attribute. These marginal utilities influence the probability he or she will choose a particular alternative. Overall, respondents prefer beaches with better water quality, less sediments and increasing fish populations. This may be seen by looking at the sign and significance of the parameter estimates for $W Q, S E D$ and FISH. Distance also plays an important role and, as expected, the longer the drive the less preferred a beach, other things being equal.

The next model (Table 6), presented as model B, accounts for the emotional treatments of the experiment. In addition to the main effects of attributes on choices, each attribute's mean and standard deviation is interacted with a dummy representing being exposed to the sadnessor happiness- inducing film clip, relative to the neutral treatment. In model C (Table 7) there is only one set of interactions for being treated in general (with either happy or sad movies 
Table 5 Likelihood ratio test results of the constraints associated with the effects of emotional treatments and self-reported emotional states on individuals' preference or scale parameters

\begin{tabular}{lccc}
\hline $\begin{array}{l}\text { Test performed (models } \\
\text { compared) }\end{array}$ & $\begin{array}{l}\text { Likelihood ratio } \\
\text { test statistic }\end{array}$ & $\begin{array}{l}\text { Degrees of freedom (number of } \\
\text { equality constraints imposed) }\end{array}$ & $P$ value \\
\hline B vs. C & 6.4874 & 14 & 0.9527 \\
B vs. D & 19.6852 & 30 & 0.9245 \\
B vs. A & 23.7932 & 32 & 0.8518 \\
C vs. E & 9.9033 & 15 & 0.8258 \\
C vs. A & 10.5954 & 16 & 0.8337 \\
D vs. E & 3.4159 & 1 & 0.0646 \\
D vs. A & 4.1080 & 2 & 0.1282 \\
E vs. A & 0.6921 & 1 & 0.4055 \\
F vs. H & 15.3507 & 30 & 0.9876 \\
F vs. A & 23.6707 & 32 & 0.8561 \\
G vs. I & 13.9239 & 30 & 0.9945 \\
G vs. A & 15.6048 & 32 & 0.9934 \\
\hline
\end{tabular}

compared to the neutral movie clips), and models D and E include interactions with dummies associated emotional treatments (separate or combined, respectively) as explanatory variables of scale, rather than mean and standard deviation of each preference parameter.

Our research hypotheses are tested using likelihood ratio (LR) tests, the results of which are provided in Table 5. $H_{0}^{1}$ (individuals in a sad or a happy (i.e., non-neutral) emotional state will state different preferences for changes in an environmental good than those in a neutral emotional state) can be tested by restricting the model B to model D, i.e. constraining all preference parameters to equal across the neutral, happy and sad treatments, while allowing for possible scale differences resulting from treatments. This hypothesis is rejected, as the LR test result shows that such a constraint does not significantly worsen the explanatory power of the model. There are no statistically significant differences between preference parameters between the treatments. In fact, the same also holds for the scale differences, as illustrated by comparing model $\mathrm{D}$ with model $\mathrm{A}$, i.e. testing if treatment-related covariates of scale are significant. This leads to rejecting $H_{0}^{3}$ (individuals in a sad or happy (i.e., non-neutral) state will display a different randomness of stated choices than individuals in a neutral state).

Similarly, by testing if restricting the model B to model C leads to significant decrease in the explanatory power, we are able to reject our $H_{0}^{2}$ (individuals who are in a happy emotional state will state different preferences for changes in an environmental good than those in a sad emotional state). We find that the preferences of those who were in a happy treatment are not statistically different from the preferences of those who were in a sad treatment. The same holds for scale differences - by comparing the model D with the model E we are able to reject $H_{0}^{4}$ (individuals in a happy emotional state will display a different randomness of stated choices than individuals in a sad emotional state).

Table 5 also includes the results of other tests that could be of use in examining whether the emotional treatments influenced preference or scale parameters. In all cases, the restrictions cannot be rejected, i.e. we find no emotional treatment-driven statistical differences in preference or scale parameters. Even though a few interactions with standard deviations appear significant in model $\mathrm{B}$ and $\mathrm{C}$, we do not find consistent evidence that exposing respon- 
dents to emotional treatments consistently influences their stated preferences. Since WTP for a marginal change in any attribute is given by dividing the coefficient on that attribute by the coefficient on travel distance as a proxy for price, and emotional treatment makes no significant change to either the denominator or the numerator, there are thus no significant effects on WTP.

\subsection{Robustness Tests and Alternative Explanations}

Our null results may have come about for a number of reasons. In this section we probe the robustness of our result and examine alternative explanations.

One question which might be raised about the robustness of the hypotheses tests concerns how long the induced emotional states persisted in our experiment. It has been demonstrated that participants with severe amnesia, and who thus quickly "forgot" the content of the film clips, still experienced the experimentally-induced emotions (Feinstein et al. 2010; see also Andrade and Ariely 2009). Despite such evidence, and despite the emotional treatments having a statistically significant effect for the self-declared emotional states (Table 3) which were elicited after all choice tasks were completed, it might still be thought that the effects of viewing any of the films would be stronger, the closer in time choices are made to the film viewing. Note that stated preferences might change over a task sequence for many reasons such as preference learning, task familiarity and the increasing use of heuristics, so that identifying the time-dependent effects of film viewing on choices across a sequence would be difficult. Nevertheless, we compared the MXL model preference parameter interactions with treatment between the first 4 and all eight choices. In none of these cases were treatment effects significant, so that there does not seem to be a time proximity effect for the emotional manipulation in this case.

We next wondered whether, despite no effect of the emotional treatments on the preferences respondents displayed for beach qualities, respondents' self-reported emotional states influenced their choices, and hence their stated preferences and scale. To do this, we used each of the two normalized ${ }^{9}$ 7-point Likert scale responses mentioned above (happy-sad, bad-good), as explanatory variables of respondents' preferences. Tables 8 and 9 contain the results. In model $\mathrm{F}$ they were interacted with the mean and the standard deviation of each preference parameter. In model G, their absolute strength (measured as deviation from the neutral state) was used. The respective models in which they enter as interactions of scale are model $\mathrm{H}$ and model I. As illustrated by the test results, presented in Table 5, we found that feeling sad and bad or happy and good did not significantly influence individuals' stated preferences for beach qualities or the randomness of their responses. This was irrespective of whether the self-reports were measured on a negative/positive scale (model F, model H) or on an absolute arousal scale, which reflected how far away from a neutral state a respondent was on each scale (model G, model I).

Another concern with the results reported here is whether the sample is large enough to be able to detect a significant effect of the treatment on preferences. We thus conducted a simulation which shows that conditional on our sample size and resulting average levels of the estimates of attribute parameters, as well as the standard errors resulting from the mixed logit model, we would identify significant treatment effects if they were larger than $14.4 \%$ (at the 0.1 confidence level) or $17.1 \%$ (at the 0.05 confidence level) of the mean attribute levels. In other words, if the treatments made respondents' preference parameters change by more than 14 or $17 \%$, respectively, then we would be able to observe a statistically significant effect

9 The variables were normalized so that each one's mean was equal to 0 and standard deviation equal to 1. 
in our sample. ${ }^{10}$ For comparison purposes the mean of the absolute values of the estimated (insignificant) shifts indicated by model B are $20 \%$ of attribute parameters.

We also investigated whether peoples' experience with the good (beach visits) helps determine whether emotional treatment has an effect on choices. The only variable which we can use for controlling respondents' previous recreation behaviour is the number of trips to beaches a respondent made in the last 12 months. All our respondents reported that they made at least one such a trip, with the median equal to 5 , mean close to 12 , and a maximum of 250 trips. The use of this variable to control for familiarity with the good did not reveal any significant effect. That is, those who visit the beach a lot show no more response to a change in their incidental emotional condition in terms of stated preferences for the attributes of the good than those who visit the beach less often. The results of the models including interactions with the number of trips are available as on-line supplementary materials to this paper, are available from the authors upon request, and at www.czaj.org.

As noted by one of our reviewers, our data may suffer from a potential problem of excluded variables. Even though we asked respondents to make choices between hypothetical beaches, it is possible that they used the distance provided to think about a particular beach which is located at a specified distance from our lab in Hamilton. If this was the case, other (not controlled for in the experiment) beach attributes and distance from Hamilton would be correlated. We acknowledge this possibility and to test if it changes our results we estimated the same set of models with the dummy coded distance parameters. This way, the dummies for the distance of 50,80 or $120 \mathrm{~km}$ can also serve as fixed effects controlling for other characteristics of beaches located within a particular distance from Hamilton. The results of such an approach were qualitatively the same-objective changes or subjective levels of emotional states did not seem to significantly influence the preference or scale parameters.

Finally, we note that we found qualitatively similar results when we applied multinomial logit, scaled multinomial logit and generalized multinomial logit models to the data (Fiebig et al. 2010). All these modelling approaches consistently showed that emotional states did not significantly influence the stated preferences of our respondents. In other words, our key result is very robust.

\section{Discussion and Conclusions}

In this paper, we speculated that variations of incidental emotions would help explain observed heterogeneity in stated preferences for environmental goods. This speculation is based on an extensive literature in behavioural science and psychology which finds that such emotions do play a role in changing how people behave, and how they value options. If stated choices are indeed affected by incidental emotions, then this would create problems for benefit-cost analysis, since it would result in a highly volatile context-dependence for welfare measures derived from stated preference methods. ${ }^{11}$

Our experiment included treatments which clearly influenced respondents' (subjective) emotional states (Table 3) — sad film clips made respondents feel sadder and worse, whilst happy clips made respondents say they felt happier and better. This means that respondents were not indifferent to the film clips and their emotional states were affected—our inducement

\footnotetext{
10 Although, note that this simulation is rather informal. If the interaction effect is not exactly equal to zero then increasing the sample would eventually make it appear significant. This is one of the reasons why some recommend against using p-values for such a purpose (Wasserstein and Lazar 2016).

11 Although we acknowledge that much of the test-retest literature fails to reject the null of stable preferences over time.
} 
of emotions was successful. However, we found that there were no significant effects of incidental emotions on stated choices. We rejected both null hypotheses relating to preference heterogeneity $\left(H_{0}^{1}, H_{0}^{2}\right)$ : inducing people into a more sad or a more happy state than neutral produced no statistically significant effects on estimated preference parameters and thus on WTP for changes in beach quality. Moreover, we failed to find any significant effect of variations in emotional state on the randomness of choice (we rejected hypotheses $H_{0}^{3}$ and $H_{0}^{4}$ ), despite work in behavioural sciences which has suggested that emotional state can impact on choice rationality (Bless et al. 1996a, b; Loewenstein et al. 2001).

An important question is thus why the effects of emotional treatment on stated preferences found here are at odds with findings in behavioural science related to actual behaviour. Indeed, in this behavioural science literature, there is very little documented evidence of instances where individual's choices were not influenced by incidental emotions (Lerner et al. 2014). There are several possible explanations. One important concern is that this may in part be the result of publication bias which is more prevalent in some fields (Yong 2012; Krawczyk 2015). However, it could also be that the null results are caused by the hypothetical nature of the stated preference exercise used here. Many of the studies that have shown that emotions play an important role in decisions are based on actual behaviour rather than stated preferences. Since actual behaviour does not always conform to intended behaviour (Carrington et al. 2010) this would suggest that the pathway by which emotion influences behaviour is not through the intermediate route of behavioural intention (stated preference).

A further explanation is that that individuals in our experiment were making choices over environmental goods (trips to beaches described in terms of coastal water quality) where the benefits of improvement are shared by many. One can speculate that choices over such goods are potentially not as sensitive to incidental emotions as decisions over consuming private goods. Future work could thus test whether we get the same null result when choices are for pure private goods, and/or in the case of actual monetary transactions. Further, it is important to highlight that we only examined the effects of one type of emotions here-incidental emotions. We did not test whether variations in other kinds of emotions have an effect on stated preferences, and thus on the stability of welfare measures. We also cannot claim that the null results obtained here for variations in incidental emotions can be generalized for other choice situations and other goods. Testing such generalizability would require further empirical work.

Finally, we note that work by several authors has established that what respondents believe the consequences of their choices to be in stated preference exercises is important for determining the demand-revealing nature of stated preference responses (Vossler et al. 2012). In the experiment reported in this paper, no measures were obtained of perceived consequentiality. Our participants were not choosing over potential increases in the supply of public goods conditional on their stated Willingness To Pay (WTP). Rather, they were choosing alternative beach trip destinations, where these choice alternatives varied in terms of their environmental attributes (the public goods of coastal water quality and marine biodiversity), and travel distance as a proxy for travel cost. It is hard to think how a consequentiality statement could have been incorporated into our experiment. There is also an interesting possibility that any finding of significant impact of emotions on WTP could in fact be a combination of two effects. The first is the effect of emotional state (sad, happy) on preferences towards any of the design attributes. The second is the possible effect of emotional state on belief in the consequences of a stated preference study. As one referee pointed out, if sad people are more willing to pay for an improvement in water quality than happy people, but also have different beliefs on the policy or payment consequentiality of their responses, then any treatment effect would be a combination of these two influences. As we have no measure of perceived consequentiality 
for participants, then this cannot be tested in the data used here. However, it is an interesting avenue for future work.

Acknowledgements We thank 2 referees and Christian Vossler for very detailed and helpful comments on the first version of this paper. We also thank George Loewenstein for helpful advice and Justin Feinstein for sharing mood induction materials. We thank MASTS (the Marine Alliance for Science and Technology Scotland) for funding the experimental work, the University of Waikato Distinguished Visitors fund for funding Hanley's research visit during which the empirical work was undertaken, and Leo Xiong for programming the experiment. MC gratefully acknowledges the support of the Polish Ministry of Science and Higher Education and the Foundation for Polish Science.

Open Access This article is distributed under the terms of the Creative Commons Attribution 4.0 International License (http://creativecommons.org/licenses/by/4.0/), which permits unrestricted use, distribution, and reproduction in any medium, provided you give appropriate credit to the original author(s) and the source, provide a link to the Creative Commons license, and indicate if changes were made.

\section{Appendix}

See Tables Tables 6, 7, 8 and 9. 


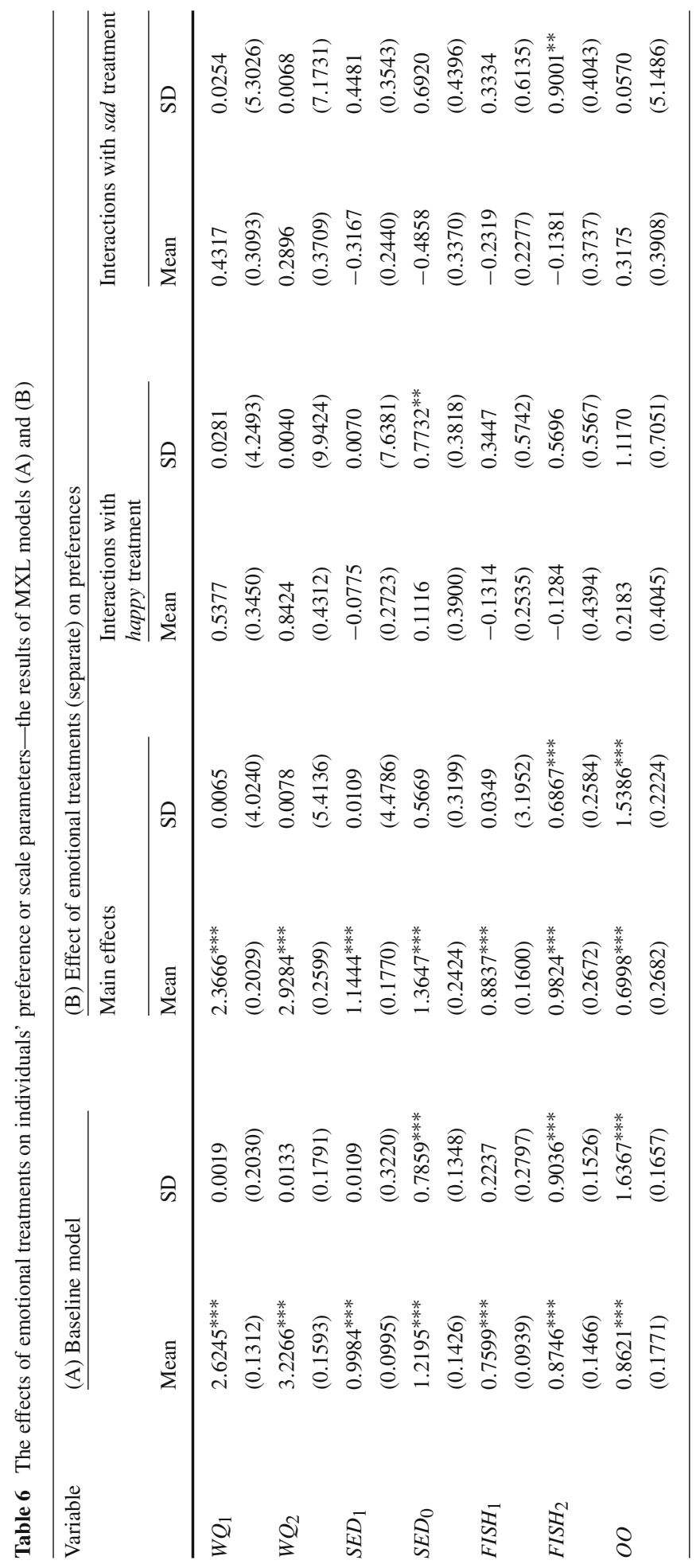




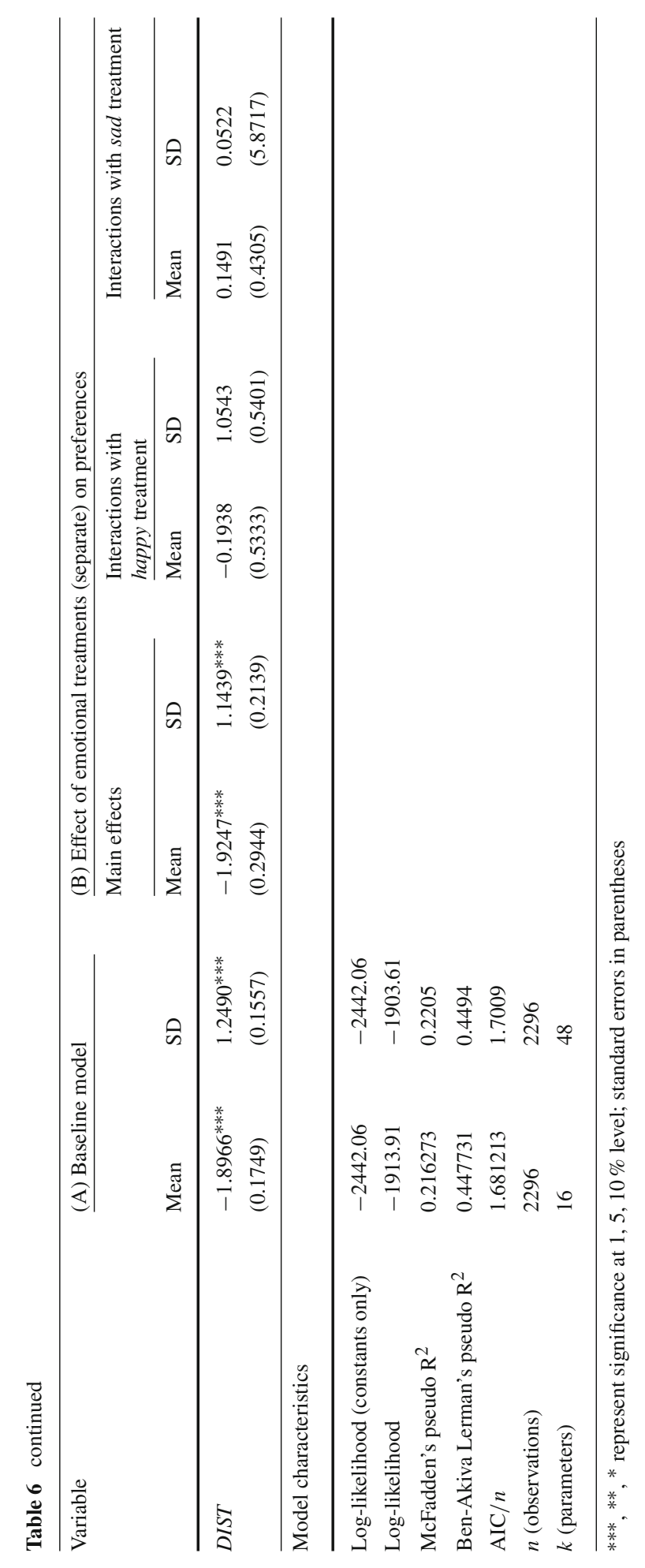




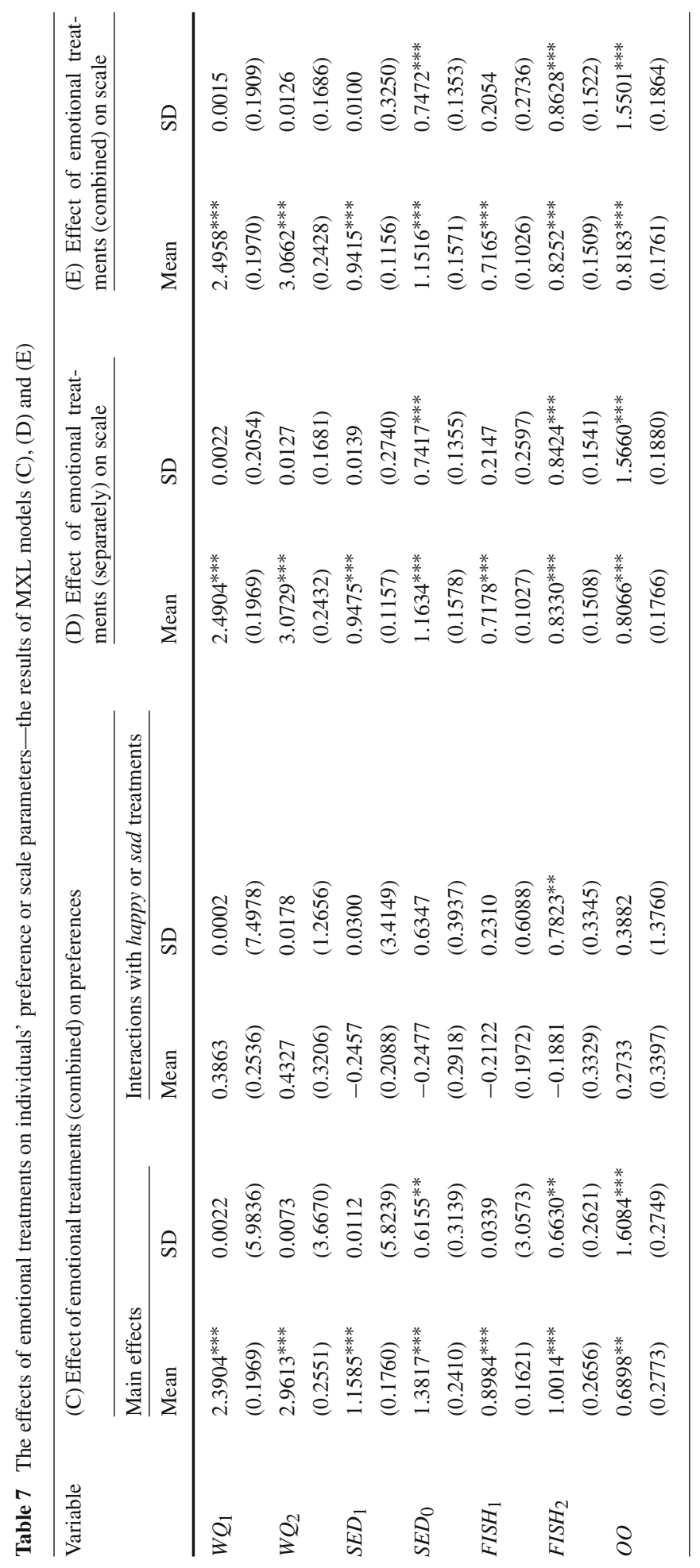




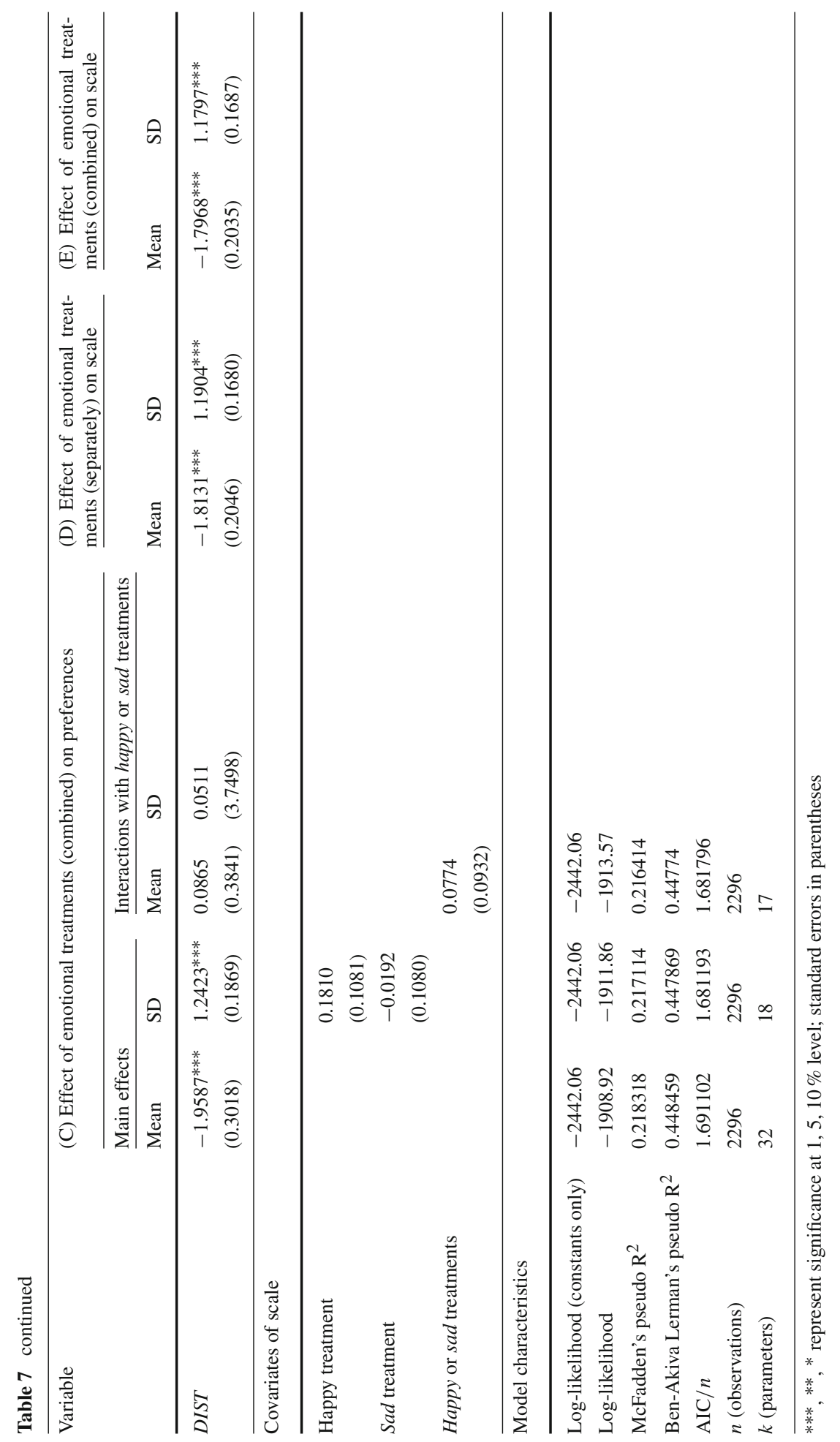


Table 8 The effects of self-reported emotional states on individuals' preference or scale parameters-the results of MXL model (F)

\begin{tabular}{|c|c|c|c|c|c|c|}
\hline \multirow[t]{3}{*}{ Variable } & \multicolumn{6}{|c|}{ (F) Effect of self-reported emotional states on preferences } \\
\hline & \multicolumn{2}{|l|}{ Main effects } & \multicolumn{2}{|c|}{$\begin{array}{l}\text { Interactions with sad- } \\
\text { happy emotional state }\end{array}$} & \multicolumn{2}{|c|}{$\begin{array}{l}\text { Interactions with bad- } \\
\text { good emotional state }\end{array}$} \\
\hline & Mean & SD & Mean & SD & Mean & $\mathrm{SD}$ \\
\hline$W Q_{1}$ & $\begin{array}{l}2.6577^{* * *} \\
(0.1355)\end{array}$ & $\begin{array}{l}0.0047 \\
(0.1994)\end{array}$ & $\begin{array}{l}0.0792 \\
(0.1924)\end{array}$ & $\begin{array}{l}0.0003 \\
(0.2443)\end{array}$ & $\begin{array}{l}-0.2566 \\
(0.1953)\end{array}$ & $\begin{array}{l}0.0046 \\
(0.2314)\end{array}$ \\
\hline$W Q_{2}$ & $\begin{array}{l}3.2657^{* * *} \\
(0.1640)\end{array}$ & $\begin{array}{l}0.0023 \\
(0.1721)\end{array}$ & $\begin{array}{l}-0.0796 \\
(0.2368)\end{array}$ & $\begin{array}{l}0.0094 \\
(0.1565)\end{array}$ & $\begin{array}{l}-0.3078 \\
(0.2434)\end{array}$ & $\begin{array}{l}0.0006 \\
(0.1674)\end{array}$ \\
\hline$S E D_{1}$ & $\begin{array}{l}1.0146^{* * *} \\
(0.1010)\end{array}$ & $\begin{array}{l}0.0143 \\
(0.2998)\end{array}$ & $\begin{array}{l}0.2891 \\
(0.1603)\end{array}$ & $\begin{array}{l}0.1473 \\
(0.3490)\end{array}$ & $\begin{array}{l}-0.3647^{* *} \\
(0.1651)\end{array}$ & $\begin{array}{l}0.0004 \\
(0.1724)\end{array}$ \\
\hline$S E D_{0}$ & $\begin{array}{l}1.2409^{* * *} \\
(0.1449)\end{array}$ & $\begin{array}{l}0.7725^{* * *} \\
(0.1769)\end{array}$ & $\begin{array}{l}0.3871 \\
(0.2270)\end{array}$ & $\begin{array}{l}0.2502 \\
(0.4047)\end{array}$ & $\begin{array}{l}-0.5455^{* *} \\
(0.2364)\end{array}$ & $\begin{array}{l}0.0503 \\
(0.3731)\end{array}$ \\
\hline $\mathrm{FISH}_{1}$ & $\begin{array}{l}0.7649 * * * \\
(0.0949)\end{array}$ & $\begin{array}{l}0.1492 \\
(0.4728)\end{array}$ & $\begin{array}{l}0.0125 \\
(0.1521)\end{array}$ & $\begin{array}{l}0.1249 \\
(0.4119)\end{array}$ & $\begin{array}{l}-0.0447 \\
(0.1558)\end{array}$ & $\begin{array}{l}0.0053 \\
(0.3855)\end{array}$ \\
\hline $\mathrm{FISH}_{2}$ & $\begin{array}{l}0.8855^{* * *} \\
(0.1488)\end{array}$ & $\begin{array}{l}0.7444^{* * *} \\
(0.2089)\end{array}$ & $\begin{array}{l}0.3043 \\
(0.2339)\end{array}$ & $\begin{array}{l}0.1423 \\
(0.4772)\end{array}$ & $\begin{array}{l}-0.4618 \\
(0.2457)\end{array}$ & $\begin{array}{l}0.5550^{* *} \\
(0.2354)\end{array}$ \\
\hline$O O$ & $\begin{array}{l}0.8701^{* * *} \\
(0.1789)\end{array}$ & $\begin{array}{l}1.5883^{* * *} \\
(0.1999)\end{array}$ & $\begin{array}{l}0.2584 \\
(0.2884)\end{array}$ & $\begin{array}{l}0.2022 \\
(0.5388)\end{array}$ & $\begin{array}{l}-0.2149 \\
(0.2939)\end{array}$ & $\begin{array}{l}0.4213 \\
(0.3986)\end{array}$ \\
\hline$D I S T$ & $\begin{array}{l}-1.9281^{* * *} \\
(0.1779)\end{array}$ & $\begin{array}{l}1.2498^{* * *} \\
(0.1678)\end{array}$ & $\begin{array}{l}-0.3333 \\
(0.2717) \\
\end{array}$ & $\begin{array}{l}0.0512 \\
(0.4343)\end{array}$ & $\begin{array}{l}0.6252^{* *} \\
(0.2831)\end{array}$ & $\begin{array}{l}0.1578 \\
(0.4932) \\
\end{array}$ \\
\hline \multicolumn{7}{|c|}{ Model characteristics } \\
\hline \multicolumn{5}{|c|}{ Log-likelihood (constants only) } & & -2442.06 \\
\hline \multicolumn{5}{|c|}{ Log-likelihood } & & -1902.08 \\
\hline \multicolumn{5}{|c|}{ McFadden's pseudo $\mathrm{R}^{2}$} & & 0.2211 \\
\hline \multicolumn{5}{|c|}{ Ben-Akiva Lerman's pseudo $\mathrm{R}^{2}$} & & 0.4501 \\
\hline \multicolumn{5}{|l|}{$\mathrm{AIC} / n$} & & 1.6996 \\
\hline \multicolumn{5}{|c|}{$n$ (observations) } & & 2296 \\
\hline \multicolumn{5}{|c|}{$k$ (parameters) } & & 48 \\
\hline
\end{tabular}

$* * *,{ }^{* *},{ }^{*}$ represent significance at $1,5,10 \%$ level; standard errors in parentheses 


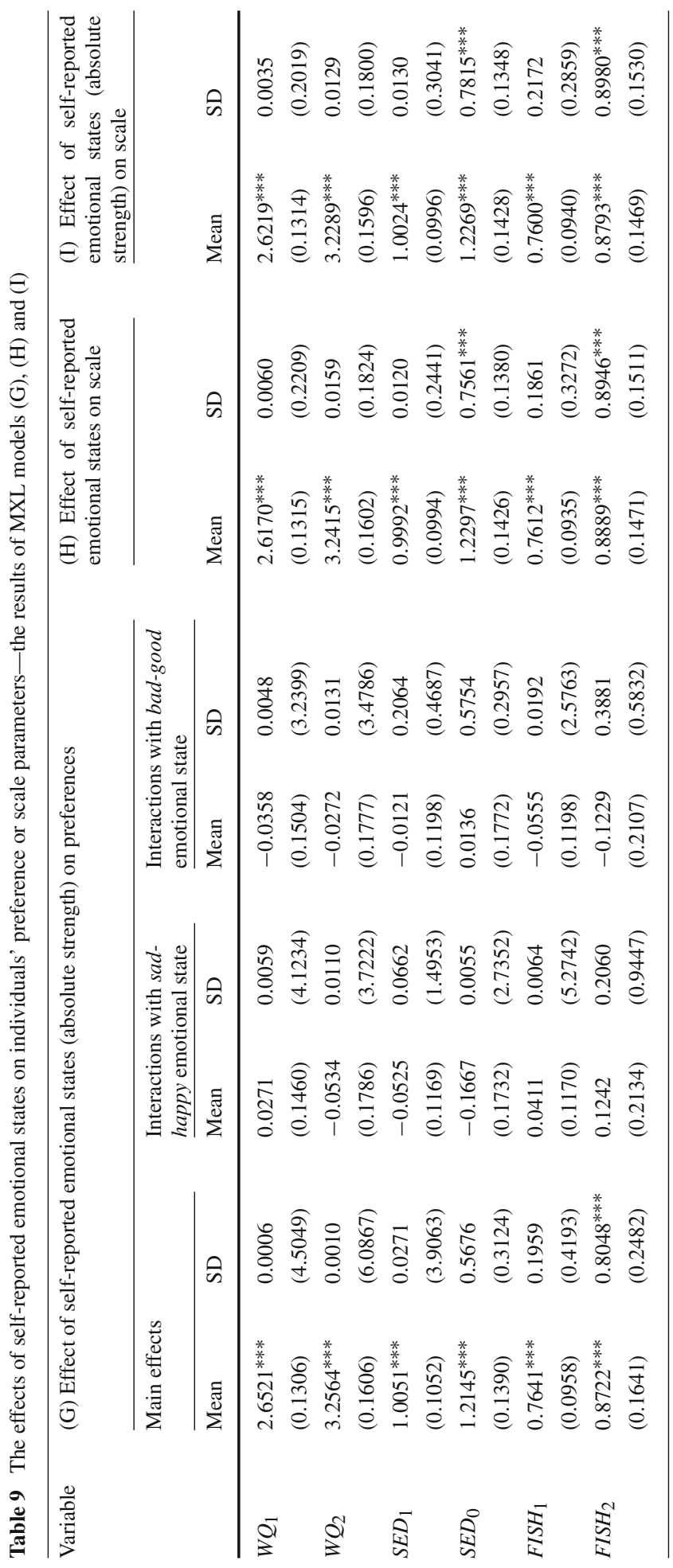




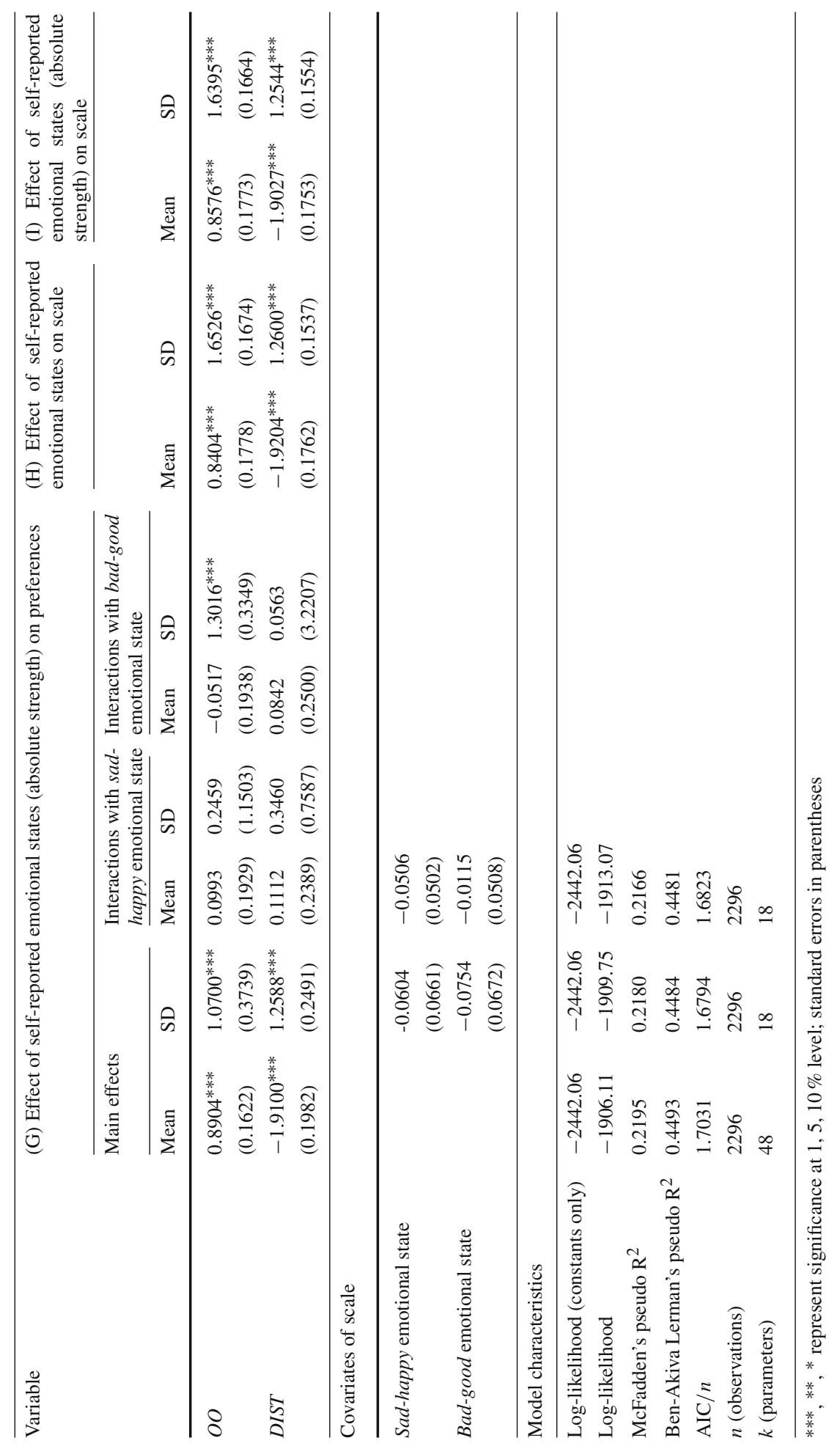




\section{References}

Ajzen I (1991) The theory of planned behavior. Organ Behav Hum Dec Process 50:179-211

Andrade EB, Ariely D (2009) The enduring impact of transient emotions on decision making. Organ Behav Hum Dec Process 109:1-8

Ariely D, Loewenstein G (2005) The heat of the moment: the effect of sexual arousal on sexual decision making. J Behav Decis Making 18:1-12

Armitage CJ, Conner M (2001) Efficacy of the theory of planned behaviour: a meta-analytic review. Br J Soc Psychol 40:471-499

Blanchette I, Richards A (2010) The influence of affect on higher level cognition: a review of research in interpretation, judgement, decision making and reasoning. Cogn Emot 24:561-595

Bless H, Clore GL, Schwarz N, Golisano V, Rabe C, Wolk M (1996a) Mood and the use of scripts: Does happy mood relate to mindlessness? J Personal Soc Psychol 71:665

Bless H, Schwarz N, Kemmelmeier M (1996b) Mood and stereotyping: affective states and the use of general knowledge structures. Eur Rev Soc Psychol 7:63-93

Bodenhausen GV, Gabriel S, Lineberger M (2000) Sadness and susceptibility to judgmental bias: the case of anchoring. Psychol Sci 11:320-324

Brown T, Kingsley D, Peterson G, Flores N, Clarke A, Birjulin A (2008) Reliability of individual valuations of public and private goods. J Public Econ 92:1595-1606

Carrington MJ, Neville BA, Whitwell GJ (2010) Why ethical consumers don't walk their talk: towards a framework for understanding the gap between the ethical purchase intentions and actual buying behaviour of ethically minded consumers. J Bus Ethics 97(1):139-158

Christie M, Hanley N, Hynes S (2007) Valuing enhancements to forest recreation using choice experiment and contingent behaviour methods. J For Econ 13:75-102

Czajkowski M, Hanley N, LaRiviere J (2015) The effects of experience on preference uncertainty: theory and empirics for public and quasi-public environmental goods. Am J Agric Econ 97:333-351

Czajkowski M, Hanley N, LaRiviere J (2016) Controlling for the effects of information in a public goods discrete choice model. Environ Resour Econ 63(3):523-544

Edmans A, Garcia D, Norli Ø (2007) Sports sentiment and stock returns. J Finance 62:1967-1998

Elster J (1998) Emotions and economic theory. J Econ Lit 36:47-74

Feinstein JS, Duff MC, Tranel D (2010) Sustained experience of emotion after loss of memory in patients with amnesia. Proc Nat Acad Sci USA 107:7674-7679

Fiebig DG, Keane MP, Louviere J, Wasi N (2010) The generalized multinomial logit model: accounting for scale and coefficient heterogeneity. Mark Sci 29(3):393-421

Ford JB, Merchant A (2010) Nostalgia drives donations: the power of charitable appeals based on emotions and intentions. J Advert Res 50:450-459

Forgas JP, East R (2008) On being happy and gullible: mood effects on skepticism and the detection of deception. J Exp Soc Psychol 44:1362-1367

Gilet AL (2008) Mood induction procedures: a critical review. Encephale 34:233-239

Greiner B (2004) Forschung und wissenschaftliches Rechnen 2003, an online recruitment system for economic experiments. In: Kremer K Macho V (eds) GWDG 63rd report society for scientific data processing, Goettingen, pp 79-93

Hanley N, Barbier EB (2009) Pricing nature: cost-benefit analysis and environmental policy. Edward Elgar, Cheltenham

Hanley N, Wright RE, Alvarez-Farizo B (2006) Estimating the economic value of improvements in river ecology using choice experiments: an application to the Water Framework Directive. J Environ Manag 78:183-193

Hensher D, Rose J, Greene W (2005) Applied choice analysis. Cambridge University Press, Cambridge

Hess S, Rose JM (2012) Can scale and coefficient heterogeneity be separated in random coefficients models? Transportation 39(6):1225-1239

Hirshleifer D, Shumway T (2003) Good day sunshine: stock returns and the weather. J Finance 58:1009-1032

Hynes S, Hanley N, Scarpa R (2008) Effects on welfare measures of alternative means of accounting for preference heterogeneity in recreational demand models. Am J Agric Econ 901011-1027

Hynes S, Hanley N, Tinch D (2013) Valuing improvements to coastal waters using choice experiments: an application to revisions of the EU Bathing Waters Directive. Mar Policy 40:137-144

Inbar Y, Gilovich T (2011) Angry (or disgusted), but adjusting? The effect of specific emotions on adjustment from self-generated anchors. Soc Psychol Personal Sci 2:563-569

Isen AM, Nygren TE, Ashby FG (1988) Influence of positive affect on the subjective utility of gains and losses: it is just not worth the risk. J Personal Soc Psychol 55:710-717 
Jacobsen JB, Hanley N (2009) Are there income effects on global willingness to pay for biodiversity conservation? Environ Resour Econ 43:137-160

Johnson FJ, Tversky A (1983) Affect, generalization, and the perception of risk. J Personal Soc Psychol 45:20-31

Kamstra MJ, Kramer LA, Levi MD (2003) Winter blues: a SAD stock market cycle. Am Econ Rev 93:324-343

Karlstrom A, Munizaga M (2002) Hybrid choice models: progress and challenges. Mark Lett 13:163-175

Kogut T, Ritov I (2005) The singularity effect of identified victims in separate and joint evaluations. Organ Behav Human Decis Process 97:106-116

Krawczyk M (2015) The search for significance: a few peculiarities in the distribution of $P$ values in experimental psychology literature. PLoS One 10(6):e0127872

LaRiviere J, Czajkowski Mikołaj, Hanley Nick et al (2014) The value of familiarity: effects of knowledge and objective signals on willingness to pay for a public good. J Environ Econ Manag 68(2):376-389

Lerner JS, Small DA, Loewenstein G (2004) Heart strings and purse strings: carryover effects of emotions on economic decisions. Psychol Sci 15:337-341

Lerner JS, Li Y, Valdesolo P, Kassam KS (2014) Emotion and decision making. Ann Rev Psychol 66:33.133.25

Liebe U, Meyerhoff J, Hartje V (2012) Test-retest reliability of choice experiments in environmental valuation. Environ Resour Econ 53:389-407

Loewenstein G (2000) Emotions in economic theory and economic behavior. Am Econ Rev 90:426-432

Loewenstein G (2010) Insufficient emotion: soul-searching by a former indicter of strong emotions. Emot Rev 2:234-239

Loewenstein G, Weber EU, Hsee CK, Welch N (2001) Risk as feelings. Psychol Bull 127:267-286

McFadden D (1974) Conditional logit analysis of qualititative choice behaviour. In: Zarembka P (ed) Frontiers in econometrics. Academic Press, New York, pp 105-142

Oswald AJ, Proto E, Sgroi D (forthcoming) Happiness and productivity. J Labor Econ

Rabin M (1998) Psychology and economics. J econ literat 36(1):11-46

Rick S, Loewenstein G (2008) The role of emotion in economic behavior. In: Lewis M, Haviland-Jones JM, Barrett LF (eds) Handbook of emotions, 3rd edn. Guilford, New York

Rottenberg L, Ray RR, Gross JJ (2007) Emotion elicitation using films. In: Coan JA, Allen JJB (eds) The handbook of emotion elicitation and assessment. Oxford University Press, New York, pp 9-28

Ruthig JC, Perry RP, Hladkyj S, Hall NC, Pekrun R, Chipperfield JG (2007) Perceived control and emotions: interactive effects on performance in achievement settings. Soc Psychol Educ 11:161-180

Schaafsma M, Brouwer R, Gilbert A, van den Berghy J, Wagtendonk A (2013) Estimation of distance-decay functions to account for substitution and spatial heterogeneity in stated preference research. Land Econ 89:514-537

Schaefer A, Nils F, Sanchez X, Philippot P (2010) Assessing the effectiveness of a large database of emotioneliciting films: a new tool for emotion researchers. Cogn Emot 24:1153-1172

Schwarz N, Clore GL (1983) Mood, misattribution, and judgments of well-being: Informative and directive functions of affective states. J Personal Soc Psychol 45:513-523

Small DA, Loewenstein G (2003) Helping a victim or helping the victim: altruism and identifiablity. J Risk Uncertainty 26:5-16

Termansen M, McClean C, Jensen FS (2013) Modelling and mapping spatial heterogeneity in forest recreation services. Ecol Econ 92:48-57

Van Boven L, Loewenstein G, Welch E, Dunning D (2012) The illusion of courage in self-predictions: mispredicting one's own behavior in embarrassing situations. J Behav Dec Mak 25:1-12

Vossler CA, Doyon M, Rondeau D (2012) Truth in consequentiality: theory and field evidence on discrete choice experiments. Am Econ J Microecon 4:145-171

Wasserstein RL, Lazar NA (2016) The ASA's statement on p-values: context, process, and purpose. Am Stat 70(2):129-133

Westermann R, Spies K, Stahl G, Hesses FW (1996) Relative effectiveness and validity of mood induction procedures: a meta-analysis. Eur J Soc Psychol 26:557-580

Yong E (2012) Replication studies: bad copy. Nature 485:298-300 